es/onshore-production.html (дата обращения 01.11.2021)

3. Пономарев П.С. Вопросы рацио- нальной эксплуатации газотурбинных установок: учебное пособие. - Уфа: ГОУ ВПО УГНТУ, 2003. $-88 \mathrm{c}$.

УДК .621.31

Бабич Дмитрий Петрович,

обучаюшийся группы КТЭм-20-1,

ФГБОУ ВО «Иркутский национальныій исследовательский технический университет», e-mail:mitka@bk.ru

Сартаков Валерий Дмитриевич, к.т.н., дочент, профессор кафедры «Электропривод и электрический транспорт», ФГБОУ ВО «Иркутский национальный исследовательский технический университет»,

ИССЛЕДОВАНИЕ ОСОБЕННОСТЕЙ СИСТЕМЫ ЭЛЕКТРОСНАБЖЕНИЯ ТОРГОВОГО ЦЕНТРА

Babich D. P., Sartakov V. D.

\title{
RESEARCH OF PECULIARITIES OF THE POWER SUPPLY SYSTEM OF THE SHOPPING CENTER
}

Аннотация. Проведено исследование особенностей и технических решений электроснабжения, освещения и электрического обогрева торгового иентра.

Ключевые слова: электроэнергетика, электрообогрев, освещение.

Abstract. Structuring of the undergraduate program block related to the practical training traversed by students at electric power enterprises in the light of a new vision for the training of a modern engineer using the Moodle distance learning system and modern case study methodology is considered.

Keywords: practice, electric power industry, distance learning, Moodle, case methodology.

К торговым центрам применяются особые меры безопасности. Эти меры относятся не только непосредственно к угрозе террористического влияния или пожарной безопасности, но и к безопасности инфраструктуры обеспечения здания.

По степени обеспечения надежности электроснабжения электроприемники здания относятся к потребителям II категории; эвакуационное освещение, приборы охраннопожарной сигнализации (ОПС), электрозадвижки пожаротушения и дымовая вентиляция к I категории.

Установленная мощность электроприемников ТЦ составляет 2392,15 кВт, в том числе электроотопление - 438 кВт, вентиляция (включая электрокалориферы) - 1446,3 кВт.

Питание осуществляется двумя кабельными линиями на напряжение 6 кВ через трансформаторную подстанцию и распределяется к электроприемникам торговых залов от вводно-распределительных устройств (ВРУ). В здании принята система заземления типа TN-C-S с нулевым рабочим (N) и за- щитным (РЕ) проводниками, работающими раздельно после шин ВРУ. Однофазные сети выполнены в трехпроводном исполнении, а трехфазные - в пятипроводном. Согласно ГОСТ Р5046-92, кабели идентифицируются по цвету по всей длине проводника окраской изоляции.

На вводе в здание выполнен контур повторного заземления, состоящий из трёх стальных электродов, сечением $63 \times 63 \times 6$ мм длиной 3 м, установленных вертикально в земле на расстоянии 5 м друг от друга и соединенных на глубине 0,5 м полосовой сталью 40х4 мм. Шины РЕ вводных устройств соединяются проводом ПВ1 сечением 50 мм $^{2}$ с главными заземляющими шинами (ГЗШ), установленными в электрощитовых. Каждая ГЗЩ соединяется стальными полосами сечением 40х5 мм с наружным контуром заземления. К ГЗШ проводом ПВ1 - 1х25 мм также присоединяются все корпуса шкафов управления, трубы водопровода, канализации, металлические короба вентсистем и металлоконструкция здания как дополнительная система уравнивания потенциалов. 
Согласно инструкции РД 34.21.122-87, здание торгово-офисного центра подлежит защите от прямых ударов молний. В качестве молниеприёмника используется сетка с шагом ячеи $10 \times 10$ м, от которой по фасаду здания проложены токоотводы, присоединенные к заземляющим контурам. Токоотводы и сетка выполняются из круглой стали диаметром 8 мм. Заземляющий контур выполняется аналогично контуру повторного заземления.

В качестве защитной и коммутационной аппаратуры в щитах применены автоматические выключатели. Питание электроприемников, относящихся к I категории электроснабжения, осуществляется через ящики автоматического ввода резерва (АВР) типа ЩАП-40А. Электропитание групповых распределительных щитков выполнено по принципу: один автоматических выключатель ВРУ - один щиток. Питание щита электрического освещения и щита аварийного освещения предусмотрено от отдельных автоматических выключателей ВРУ.

Основными потребителями электроэнергии являются освещение, отопление, тепловые завесы, электрокалориферы, приточная и вытяжная вентиляция и дымососы.

Наружное освещение территории, прилегающей к торговому центру, выполнено светодиодными прожекторами СДО8 мощностью $100 \mathrm{Bт}$, напряжением $230 \mathrm{~B}$, цветовой температурой $6500 \mathrm{~K}$, световым потоком 9500 лм и классом защиты IP65. Управление освещением принято местное от ящиков освещения и дистанционное с поста охраны офисного центра. Расчетная мощность наружного освещения 12 кВт.

Для освещения внутри помещений выделено рабочее освещение и эвакуационное освещение. Освещенность принята по СанПиН 2.2.1.1278-03 440 лк для торговых залов, 300 лк для офисных помещений. В качестве источников света приняты подвесные светодиодные светильники. Светильники эвакуационного освещения запитаны от параллельной линии, запитанной от отдельной ячейки трансформаторной подстанции энергоснабжающей организации. Управление освещением торговых залов осуществляется с осветительных щитков и выключателями, установленными у входов в помещения. Особенностью включения светодиодных светильников является наличие драйвера тока с мощными конденсаторами на входе, что приводит к значительным пусковым токам, и как следствие срабатывание автоматических выключателей, питающих силовую часть схемы. Для включения света в ТЦ используются контакторы типа КМЭК. Контактор для конденсатора КМЭК это специализированный контактор двухступенчатого включения для коммутации конденсаторов в установках компенсации реактивной мощности (УКРМ). Световые указатели «Выход» управляются со щитков ОПС.

Для обеспечения тепла торгового центра зачастую используются следующие виды отопления:

- водяное отопление;

- воздушное отопление;

- электрическое отопление.

В ТЦ используется потолочное электрическое отопление и калориферное воздушное отопление в качестве вспомогательного.

Согласно СНиП 41-01-2003 «ОТОПЛЕНИЕ, ВЕНТИЛЯЦИЯ И КОНДИЦИОНИPOВАНИЕ», торговые залы при электрическом отоплении должны оснащаться обогревателями с температурой на теплоотдающей поверхности не более $150^{\circ} \mathrm{C}$. (Приложение Б, Б.7.). Температура поверхности используемых инфракрасных обогревателей типа Эргна 0,5/220(п)КТ при температуре окружающей среды $+20^{\circ} \mathrm{C}$ равна $120-130^{\circ} \mathrm{C}$. Основное время работают только инфракрасные излучатели. Такое решение избавило от дорогостоящей прокладки и внутренней разводки водяного отопления, а также от шума воздушного отопления.

Дополнительно к управлению инфракрасными обогревателями внедрена система фазного регулирования на твердотельных реле FOTEK SSR-60VA. Управление ведется переменными резисторами 470 кОм/2 Вт. Это позволяет осуществлять регулирование мощности обогрева и финансовую экономию в часы пиковой стоимости электроэнергии. В существующей системе применяется тариф с почасовой стоимостью в зависимости от общей потребляемой мощности в городе. В организации производится анализ расходов на потребление электроэнергии и снижается потребление электроэнергии с 9 до 10 утра, так как в это время самый дорогой тариф.

Для приточных вентиляционных установок применена система Clima со шкафом управления VS, обеспечивающая: 
- контроль и регулирование температуры приточного воздуха и воздуха в помещении;

- контроль температуры воздуха за калорифером;

- контроль запыленности воздушного фильтра;

- защита электрического нагревателя от повышения температуры выше допустимой.

Bce средства автоматизации подключены к шкафу управления вентагрегатом. Также предусмотрено отключение аппаратов вентиляции при пожаре по сигналу ОПС. Одновременно, включаются дымососы.

Противопожарная защита включает в себя следующие средства:

- автоматическая установка пожаротушения - предназначена для локализации и тушения очага пожара в первоначальный момент его возникновения;

- автоматическая пожарная сигнализация (АПС) - предназначена для обнаружения пожара и извещения о нём находящихся в здании людей;

- система оповещения и управления эвакуацией (СОУЭ) - предназначена для своевременного сообщения людям информации о возникновении пожара, необходимости и путях эвакуации.

Проектом эти системы увязаны в единую сеть, разработаны инструкции обслуживания, ремонтов, поведения персонала, назначены ответственные лица, ведутся журналы в соответствии с действующими нормативными документами.

Учет электроэнергии предусмотрен на вводных панелях трехфазными электронными счетчиками, включенными через трансформаторы тока. Сбор почасовых показаний осуществляется по протоколу RS-485 в компьютер для анализа и формирования отчетов.

В современных системах электроснабжения применяются компьютерные средства измерения потребляемой электрической энергии. Эти средства требуют использования дискретных математических моделей.

Математические модели (ММ) реализации микропроцессорных измерительных приборов (МПИП) строятся на соответствующих принципах, изложенных в инструкции [2].

Рассмотрим вариант разработки ММ цифрового прибора для измерения полной мощности в однофазной цепи. Для создания модели прибора производится квантование тока и напряжения во времени и по уровню с помощью аналого-цифрового преобразователя, т.е. получение значений тока и напряжения $i_{K}$ и $u_{K}$, «огибающие» которых изменяются по периодическому закону с периодом, равным $T$.

На следующем этапе реализации математической модели МПИП полной мощности производится возведением в квадрат дискретных значений $i_{K}$ и $u_{K}$, т.е. определение $i_{K}^{2}$ и $u_{K}^{2}$.

Для вычисления полной мощности необходимо определить действующие значения периодического тока и напряжения. Для этого производится суммирование значений $i_{K}^{2}$ и $u_{K}^{2}$ для разных интервалов дискретности « $K »$, изменяющихся от 1 до «n» в пределах периода $T$. Действующее значение тока равно $I=\frac{1}{T} \cdot \sqrt{\int_{0}^{T} i_{K}^{2} \cdot d t}$. Действующее значение напряжение вычисляется по аналогичному выражению $U=\frac{1}{T} \cdot \sqrt{\int_{0}^{T} u_{K}^{2} \cdot d t}$.

Полная мощность в однофазной цепи вычисляется по уравнению $S=U \cdot I$.

MМ при измерении активной мощности в однофазной цепи содержит аналогичные дискретные математические операции. С этой целью вычисляются произведения мгновенных значений мощностей $p_{K}=u_{K} \cdot i_{K}$ для всех интервалов квантования в пределах от 1 до n. Следующей операцией является суммирование произведений мгновенных значений мощностей $p_{K}=u_{K} \cdot i_{K}$ на величину шага дискретности $\Delta t$ для всех интервалов квантования в пределах от 1 до «n» $\sum_{K=1}^{n} p_{K} \cdot \Delta t$. Эту сумму следует разделить на величину периода $T$ и получить $P=\frac{1}{T} \cdot \sum_{K=1}^{n} p_{K} \cdot \Delta t$ и затем определить дискретное выражение для активной мощности в однофазной цепи. Активная мощность в трехфазной цепи определяется по похожим дискретным уравнениям.

Подобные уравнения можно получить при определении электрической энергии. 